Portland State University

PDXScholar

\title{
Towards a Philosophy of Expertise: the Novice- Expert Problem and Contemporary Applications
}

Cindyjo Keomani Boungnavath

Portland State University

Follow this and additional works at: https://pdxscholar.library.pdx.edu/honorstheses

Let us know how access to this document benefits you.

\section{Recommended Citation}

Boungnavath, Cindyjo Keomani, "Towards a Philosophy of Expertise: the Novice-Expert Problem and Contemporary Applications" (2017). University Honors Theses. Paper 369.

https://doi.org/10.15760/honors.362

This Thesis is brought to you for free and open access. It has been accepted for inclusion in University Honors Theses by an authorized administrator of PDXScholar. Please contact us if we can make this document more accessible: pdxscholar@pdx.edu. 


\title{
PORTLAND STATE UNIVERSITY
}

\author{
An Undergraduate Honors Thesis Submitted To The \\ University Honors College \\ $\&$ \\ Department of Philosophy
}

In Partial Fulfillment of The Requirements For The Degree of Bachelors of Science

Towards A Philosophy of Expertise: The Novice-Expert Problem And

Contemporary Applications

Written By: Cindyjo Keomani Boungnavath

Thesis Advisor: Dr. Angela Coventry

Submitted On: 25 March 2017

\begin{abstract}
:
The problem of expert analysis and testimony is a relevant and commonplace issue that proves to be typical in day-to-day interaction. This is seen in both areas within academia as well as public life. To frame this issue in a contemporary context, I begin my analysis of the novice-expert problem by surveying the climate change debate. I provide brief descriptions of both dominant positions in the debate while exposing the task of a novice to resolve conflicting expert opinions. In public policy, it is usual that the policymaker is considered the novice in such relationship, therefore featuring the issue's importance. The novice-expert problem is explicated here through its function within public policy regarding legislative decision-making. Epistemologist Alvin Goldman suggests that a novice has the ability to consult five sources of evidence in order to base the novice-expert relationship on grounds of justified credence rather than on blind trust. A component extracted from this list is the strategy of 'going by the numbers', which Goldman refutes. Notwithstanding, Goldman's argument is met with contention for reasons equally reasonable, defended by David Coady. It is my objective to bridge the gap between both positions through the application of my own epistemological analysis (from the position of a novice). I propose conditions whereby 'going by the numbers' is substantiated therefore clarifying the issue a little more.
\end{abstract}




\section{Table of Contents}

\section{Section I}

Title Page

\section{Section II}

Table of Contents

Section III

Climate Science \& The Climate Change Conversation

Section IV

The Novice-Expert Problem

\section{Section V}

Expertise \& Background Information

\section{Section VI}

Relevance To Public Policy

\section{Section VII}

Going By The Numbers.

\section{Section VIII}

Conclusion

\section{Section IX}




\section{Climate Science \& The Climate Change Conversation}

To begin, I'd like to provide a brief introduction to climate science that will begin our discussion of the novice-expert problem (where a novice is unable to adjudicate disagreement between experts). The novice-expert problem as seen in the climate change quandary is one instance where a novice encounters competing arguments made by experts. It is the objective of a novice to arbitrate the positions and appropriately choose which is defended with the proper support of evidence. The position in which a novice occupies in the novice-expert relationship is one of vulnerability. It is important for a novice to engage in activities that seek different forms of supporting evidence (i.e. empirical data, credentials, testimony, track records, etc.) in order to justify what information is being considered for intellectual guidance. By offering a summary of climate science, I endeavor to provide an explanation from which the climate change debate derives its purpose (and where we begin to explore the novice-expert dilemma).

Considering the total radiation we receive from the sun, roughly one-third is reflected back into space while the remaining two-thirds are absorbed by the earth's atmosphere, prompting a heating effect ( $F A Q$ 1.3). This process of the planet's temperature fluctuation will continue so long as radiative equilibrium (outgoing energy=incoming energy) is not reached (Frierson). Because most of the radiation from the sun is in the form of small wavelengths the earth's atmosphere easily absorbs them. Inversely, it is more difficult for radiation in the form of long wavelengths to escape the atmosphere because greenhouse gases absorb and radiate energy back to earth in all directions. As a result, greenhouse gases increase the amount of radiation being absorbed by inhibiting long wavelengths to exit the atmosphere.

Consider the following positions of the climate change debate: 
Some experts in the climate change debate argue that the principal driving force for climate change is due largely in part by human activity (through processes like combustion and fossil fuel use). Others however argue it is inherently due to the natural fluctuation of our climate system that prompt these extreme weather changes.

Those arguing that climate change is a current danger also claim the main issue is the rate at which the earth is warming, referencing historical climate data over time. Carbon dioxide is the chief climate-regulating gas of our entire climate system. Data extracted in various forms including: ice core samples, tree ring samples, shift in migration patterns, plant fertilization, and ocean sediment to name a few, reveal evidence for phenomena such as: ocean acidification, shrinking ice sheets, and the rise of global temperatures. With the development in industry, there is an increase with the rate at which fossil fuels are burned to satisfy such high demands. This natural resource, when burned, releases carbon dioxide into the atmosphere significantly affecting the composition and dynamics of the ocean system. As the atmosphere's carbon dioxide content increases, a large portion of it is absorbed by the oceans causing the ph level of oceans to decrease (or acidify). The accumulation of carbon dioxide in our atmosphere should be done with caution for the simple fact that the oceans regulate the earth's temperature and carbon cycle. As the climate becomes warmer (and oceans swell due to this increase in temperature), ice structures melt and cause an increase in sea levels (prompting floods, heat waves, storms, etc.). There is a large global population that relies on oceans to provide them their primary source of protein which contributes to the severity of ocean acidification. This poses a reasonable worry for those that are being affected and will be affected by the long-term ramifications associated 
with global warming. This dilemma and the variety of responses to it can be characterized by a variation of Pascal's wager. Consider the following table as a representation of the debate:

\begin{tabular}{|l|l|l|}
\hline & $\begin{array}{l}\text { Catastrophic Anthropogenic } \\
\text { Climate Change }\end{array}$ & $\begin{array}{l}\text { (Naturally occurring) Climate } \\
\text { Change }\end{array}$ \\
\hline Conservation efforts & $\begin{array}{l}\text { Current and future } \\
\text { generations are positively } \\
\text { affected }\end{array}$ & No rewards \\
\hline Doing nothing & $\begin{array}{l}\text { Current and future } \\
\text { generations are negatively } \\
\text { affected }\end{array}$ \\
\hline
\end{tabular}

Due to the potential benefits far outweighing the costs, it makes for a rational decision to accommodate the theory more conservative in nature because there are less risks associated with it (in this case). As seen above, it would be prudent to choose a path that results in the best situation possible, that being the health of the environment and well-being of humans. Accordingly, it is probably best to edge on the side of caution that tends toward safety and less risk. The considerable body of evidence gathered by a wide range of scientists is used to justify why climate change should be addressed now and the appropriate measures be taken to prevent further harm of the environment. The very nature of data in support of this position is such that proves scientific methods can be applied to anything observable and falsifiable, therefore exposing objective truth.

In contrast to this argument is a position held by energy theorist, and philosopher, Alex Epstein who ultimately rejects current catastrophic climate change. Epstein argues that the framework in which we view and discuss climate change is largely in terms of the carbon dioxide argument (that carbon dioxide emissions are chiefly human-induced). It is important to 
be clear in framing any discussion what the specific concern is; in this case, are we concerned about carbon dioxide emissions or are we concerned about human well-being (Epstein advocating for the latter)? Worth noting is that Epstein acknowledges climate variation as a constant of nature with human activity functioning within these parameters. To view human activity in this way would indicate human life is intrinsically anti-environment. Epstein goes on to clarify two interpretations of (the natural) environment, which is pivotal to this dispute: 1) nature is an external force that acts upon humans; and 2) nature acts without any regard to humans. I think this is a critical distinction because it reveals the overarching narrative accepted as the relationship between human life and nature. Humans operate and live within the natural system and are agents of environmental influence (much like any living organism); an appeal to think otherwise would slip into a naturalistic fallacy, a perspective equating natural to good. This is fundamentally problematic due to the general consensus that humans exist external to nature and are thereafter affected $b y$ it. Climate is ever-changing and the language we prescribe to it implies an anthropomorphic position. Nature does not have intention, nor does it perform favoritism, it is rather nothing we think it to be because its existence simply is. Humans actively engage in activities that transform and modify climate at a local level which makes the planet more accommodating, ergo increasing human life expectancy. Epstein articulates that environmentalists are most concerned about reducing human impact on earth, but Epstein correlates that to the presence of human life. No other species of animal, as far as we know, is consciously making an effort to alter their environmental impact, so why are we (given that human activity is commensurate to birds building nests)? Epstein lastly mentions something he 
calls the "pristine planet premise" (The Rubin Report) by which the view held is mother nature handed us a perfect world and any impact we have upon it is detrimental.

Though both sides present plausible arguments in support of and against current climate catastrophe, there arises a conflict in expert opinion. Thus, begins our discussion of the novice-expert problem; what does a novice do in the encounter of splitting views? 


\section{The Novice-Expert Problem}

In the event that a non-expert is confronted with the issue described above, the concern of expertise is accentuated. The idea of expertise is based on an epistemological inequality between the novice and expert who is "less likely to be mistaken and likely to be less mistaken."

(Hardwig, Toward an Ethics of Expertise 2) Doubt is raised in any debate where a non-expert is challenged with competing messages from experts. When a novice is left to arbitrate between several arguments defended by experts, this can cause a reluctancy toward agreement due to the discrepancy and lack of cooperation to settle the debate. Even though this conflict naturally raises doubts in a novice, the plight associated with expertise is addressed with possible solutions proposed by epistemologist, Alvin Goldman. He offers a method by which a non-expert can justifiably resolve the problem with expert tenability while also opening the discussion about the fundamental nature of expertise and its acceptance within individual discourse communities. In the following piece, my hope is to provide an analysis of Goldman's inquiry to the novice-expert problem and how it can be applied to contemporary dialogue surrounding issues of public policy. To frame this discussion, I'd like to utilize Goldman's definition of expert as well as provide information about the philosophy of expertise critiqued by persons such as: Almassi, Coady, Corry, Matheson, and Hardwig. I will also venture to mediate between Alvin Goldman and David Coady's respective accounts for 'going by the numbers' (a strategy most used in public debate where the accepted position is due to collective opinion) by proposing conditions where the strategy is most effective. ${ }^{1}$

\footnotetext{
${ }^{1}$ As a side note, I will be using the terms novice and non-expert interchangeably.
} 


\section{Expertise \& Background Information}

In this discussion, an expert is defined as "someone who possesses an extensive fund of knowledge (true belief) and set of methods for apt and successful deployment of this knowledge [toward developing] new questions in the domain" (Goldman 92). Goldman argues that this definition suggests expertise not be viewed as wholly a comparative matter. For example, if the majority of people in a field hold many false beliefs and one person does not concede to a few of these, said person does not qualify as an expert because they lack a substantial body of true beliefs (not the amount of true beliefs compared to falsehoods held by many). The idea of evaluating expertise should be done in regards to the individual and not compared against other expertises in the interest of ensuring against expertise curves (much like grading curves). To evaluate expertise is to focus on the arguments and techniques employed that help establish and rationalize an expert's position. Goldman focuses his expert analysis on specifically cognitive experts (versus skill/know-how experts) that have an exceptional level of knowledge in a specific topic. Expertise in this sense is not concerned solely about possessing accurate information, but also the ability to apply that fund of knowledge toward generating new, significant, and productive questions. Also, it is typical for experts to possess an unusually comprehensive level of knowledge regarding primary questions (questions of interest for researchers) and secondary questions (existing evidence for primary questions) in their subject matter. This is significant because it can reduce difficulty found in the exchange of ideas that take place within the novice-expert relationship. Both parties in this case are afforded the opportunity to productively engage in dialogue that addresses the issue in a manner conducive to developing the conversation. With this goal in mind, Goldman proposes criteria a non-expert can use to 
effectively critique experts. He offers five sources of evidence a novice can apply to the novice-expert problem: consider 1) arguments in support of/against the expert's position; 2) agreement from other putative experts ${ }^{2}$ within the same field; 3) appraisals by meta-experts 3 ;) evaluation of relevant interests and biases; and 5) evidence of the expert's past track record. An interest of this paper will be directed towards points two and three, which comprise the strategy of 'going by the numbers'. This is an essential component to my conclusion through which I find a compromise between Goldman and Coady reflecting about crowd size as an indicator of expertise. Additionally, I would like to clarify that Goldman's proposition as stated is not meant as a definitive solution, but rather an exploration for reasons a novice can be supported in their deliberation of evidence. Goldman acknowledges that this area of study is non-traditional in some respects, therefore the solutions he offers are preliminary. Through this investigation, Goldman attempts to identify problems with assessing expertise through the perspective of a novice and suggests possible solutions to alleviate this dilemma.

\footnotetext{
${ }^{2}$ Specialized technical experts includes those of which are influential in their field of study concerned with methodology, resources, and contribution to the study in question, to name a few. This type of expert's position is one of high importance and considered to be germane to the relevant discussion.

${ }^{3}$ Meta-expertise is the opinions of those that are used to evaluate other expertises. This type of third-party expertise is applicable to the novice-expert problem as it identifies reasonable evidence to ground one's judgment of an expert.
} 


\section{Relevance To Public Policy}

The problem of assessing expertise makes its presence in various forms, consider the following examples: the climate change debate, medical advice from different doctors, legal advice from different lawyers, advice on civil engineering from an urban planner vs an architect, and the execution of tasks within in a 'chain of command'. Accordingly, the novice-expert problem permeates throughout much of public interaction; applying this to public policy, it is important to reduce uncertainty with complex issues in order to enable decision-making. The relevance of this toward the climate change debate is one that is currently being assessed within public policy. The issue of expertise is highlighted in this instance by the diversion of arguments presented on both sides. Though the side with greater 'numbers' argue for anthropogenic climate change, there is yet discrepancy in the debate where the lesser 'numbers' continue to resist the power of the 'numbers' (argument). Henceforth, Goldman's five sources of evidence a novice should consult can be made of use here by citing other sources of expertise. By proposing a pertinent set of criteria, his goal of substantiating a novice's position is achieved.

People are affected in noteworthy ways in regards to decisions made in public policy; due to this, it is reasonable to argue that the general public is authorized to proffer solutions for civil issues. In not doing so would provide the public with reasons to defy policymakers by their disregard of public opinion in precisely a public matter. The issue with this is when policymakers deny proven scientific data and at the same time are held responsible to enact legislation around these scientific matters (i.e. the climate change debate).

In viewing policymakers as the novice in this given situation, the novice-expert problem is made relevant. To clarify, the following will be an assessment of an epistemological approach 
(knowledge-based) toward the novice-expert problem rather than one of argumentation theory. In argumentation theory, efforts are made to establish dialectical superiority that can serve as an indication of expertise. The non-expert is ill-placed to infer the relationship between content and supporting arguments in expert conclusions. In the absence of relevant experience, a non-expert does little in contributing to the technical aspects of the discussion, nonetheless, they are considered influential in the political rather than technical realm (i.e. cost-benefit analysis). Cost-benefit analysis is the process by which pros and cons of a decision is quantified; this is done by subtracting all possible costs from the projected sum of benefits. This is a helpful tool in decision-making because it is important that policymakers reflect on all areas influenced by a decision so as to make a judgement most beneficial for a community.

In our current state of affairs, policymakers are becoming more reliant on the institution of expertise for reasons that provide an authoritative basis for drafting purposes. It is an essential responsibility of a policymaker to make decisions in both areas where they are knowledgeable and areas where they have little to no understanding. Due to this expansive range of topics policymakers influence (i.e. transportation systems, legalization of drugs, environmental policy, criminal law, etc.), their reliance on the expertise of others is crucial. It is therefore necessary that expert arguments be inspected carefully and purged of any inaccuracies ${ }^{4}$. As a result, I suspect the opinions of experts are heavily scrutinized in an effort to avoid miscalculation that can negatively affect their research methods, resources, and the policymakers that relied on their

\footnotetext{
${ }^{4}$ The problem of 'stylistic polish', and the "dark art of rhetoric" of appearing to be an expert is raised (Coady, What To Believe Now 48). Demeanor should be received with suspicion because mastering the art of debate can easily be done to form the illusion of expert. This can be done in many ways that include the manipulation of: composure, diction, style of response, argument form, body language, etc.
} 
expertise. ${ }^{5}$ A policymaker's reputation is put at risk because of this, and proves why validated expert opinion is so highly valued (for reasons such as incumbency). It is also important to inform the public with current information surrounding issues in the public sphere as it is the electorate that appoints policymakers their position of power. These same voters are voting for candidates they think are capable of implementing sensible, representational, and effective legislation that benefits a community.

Moreover, there seems to be a noticeable difference in the amount of information one has access to compared to twenty years ago. With the ability to inquire into just about anything, the internet as a tool has become ingrained in our everyday activity. We are a species that seek information and make sense of our surroundings. As the rise of an educated public (with the ease of accessing information online) enters the debate floor, the evaluation of experts is added yet another dimension. The way in which I utilize the term 'debate floor' is meant to encompass all persons who wish to engage in voicing their opinion on a particular discussion. Typically those that weigh in on a topic have at least some degree of relevant knowledge in order to inform their thought process. A forward-looking solution for dealing with the problem of expertise is to shift the focus from specialized subject matter to methods of argumentation. Doing so will allow non-experts to better assess claims of experts based on grounds of logic and argument form rather than content, which is less accessible of the two. A requirement for the comprehension of any technical debate is the possession of technical knowledge to refer to; this will help connect

\footnotetext{
${ }^{5}$ The institution of expertise is an intricate one with indefinite, flexible variables that attempt to identify experts in a field (a non-expert's task). The institution of expertise is one of dynamic relationships that include a mutual respect for each other's role in the partnership.The position of a non-expert is inherently one outside of a field's technical domain; therefore in the absence of technical knowledge or relevant experience, non-expert appraisal ought to derive from social judgements. Through the activity of forming social judgments, a decision is made by the non-expert only about who to believe because the lack of technical knowledge does not serve as ground to decide what to believe.
} 
supporting evidence to its proper conclusion. All this however, would be no direction of a novice because that would then alter the relationship from a novice-expert problem to something more of a relevant critic-expert problem (which is not the focus here). Once a novice obtains an ample amount of technical knowledge, no longer does this specific dilemma apply. The expert's argument will therefore be evaluated and defined by their ability to propose well-reasoned arguments irrespective of their credentials. By using this technique, public participation will increase and add relevant experience and opinion to the information base. Moving the discussion from closed-off quarters to a practice more representative of the public can also result in "the consideration of the full range of norms, values, interests, and preferences that might bear on a situation" (Thomas \& Buckmaster, Expertise and Public Policy: A Conceptual Guide). Henceforth, possibilities for the most effective solutions to a problem is better handled free-formed than if the discussion remained sequestered. Non-experts in this sense are considered agents in the free-flowing exchange of ideas and not merely "passive [recipients] of expert activity." (Hardwig, Toward an Ethics of Expertise 11) The ethics of expertise should be considered in the relationship between the non-expert and expert because in the event that an expert abuses their intellectual authority, the issue moves away from being a rhetorical issue to a moral one. The vulnerable position of a novice should therefore not be exploited by an expert. David Matheson, an epistemologist, makes the argument that possessing greater sensitivity in arguments may act as an indicator for greater credibility; this is due to Matheson's emphasis on maintaining moral high ground, even in instances of debate and disagreement. For Matheson, it is critical to maintain 'open-mindedness', a cognitive trait that is "recognised as a virtue in the 
pursuit of higher knowledge” (Thomas \& Buckmaster, Expertise and Public Policy: A Conceptual Guide).

It is critical that while reflecting on a body of evidence a non-expert maintain a balance between the pursuit of truth and avoidance of falsehood. Though these acts may sound synonymous, both are different outcomes regarding varying degrees of inquiry. By looking at not what means of inquiry were conducted, "we are at the mercy of our evidence". (Coady, What to Believe Now 12) Truth is a constant engagement involving current and relevant information, whereas to avoid falsehood is the active participation in the investigation of truth. This is done by putting to use techniques (such as those mentioned above) as well as performing original analysis to attest truth as an epistemic goal.

Withal, looking to its practical application, some (if not, most) beliefs are held without the proper support. Human belief systems are too comprehensive that to investigate them exhaustively and furnish conclusive evidence for each would be implausible. If intellectual autonomy is pursued across the board, within all disciplines, one could only ever hold "relatively uninformed, unreliable, crude, untested, and therefore irrational beliefs." (Hardwig, Epistemic Dependence 340) Intellectual autonomy in all areas of a person's interest is a fanciful, unrealistic ideal that cannot be attained. A paradox arising from this proposition is whether or not it is possible to know something one does not fully understand. To exemplify this idea, if a well-renowned climatologist claimed humans are the leading cause for climate change, would I as a novice be justified to know said claim based exclusively on my reliance of the expert? Is indirect knowledge a legitimate form of knowledge? The idea of being justified based on expert reputation is countered with an "...old and important idea that knowing a proposition requires 
understanding the proposition and possessing the relevant evidence for its truth.” (Hardwig, Epistemic Dependence 349) Hardwig therefore claims that (partially blind) trust plays a significant role in the ability to know anything.

I think it is helpful that expert claims be considered prima facie, and supported with empirical data thereafter (i.e. Goldman's five sources of non-expert evidence). By granting experts 'fundamental authority' for their opinions, it acts as a blind trust that is necessary for the acquisition of knowledge (as claimed by Hardwig). Incorporating the 'numbers' strategy, this should serve as empirical evidence only in situations where overwhelming numbers secure a position. I would like to reiterate that though decisions can be made about who can be considered trustworthy, the content conveyed should not by any means be considered 'known' by the non-expert (referring to the earlier paradox example). In relation to the non-expert's position to esoteric statements, it remains a task for the non-expert to justifiably determine one expert as more credible than the other on grounds of their respective practice of expertise. These efforts help a non-expert make decisions that can be rationalized and supported with evidence in order to strengthen their epistemic independence. Worth noting is that both Goldman and Coady defend a reductionist approach where the non-expert consults all bodies of evidence and performs individual analysis based on what is 'epistemologically palatable'. It is a mistake to view statements as either eso/exo-teric because any given statement is only either of the two relative to the novice's epistemic positioning; hence, the effect of statements are only ever contextual.

An interesting point to be made here is that experts can only construct their argument with the appropriate evidence if they assume the position of a non-expert themselves. In order to 
adequately evaluate issues of interest, an epistemic position is necessary in order to frame an investigation. From there, it is clarified by what methods and information are employed to make sense of an argument or presented evidence. Also worth noting is that an expert's character should be assessed as should their argument content because it can inform the novice of what their competence, motivation(s), and objective(s) are. These aspects largely influence points four and five from Goldman's list which is critical to consider. Failure to do so would result in a faulty receipt of the argument and its supporting evidence. To that end, the conclusion could only be read out of context. It is vital to frame a research question with the methods used to support a hypothesis; evidence is only ever helpful when presented in the context from which it was gathered along with the intent. In addition, a difficulty non-experts run into is having to guess whether the dominant position is due to evidential support or endorsed by the supermajority (expert that is most cited, funded, etc.). The problem of 'going by the numbers' is seen problematic in cases where 'numbers' are being misrepresented. This point emphasizes the caution that should accompany such strategy as a result of being widely used in the forming of one's opinion. Numbers are easily accessible, however just as easily manipulated. 


\section{Going By The Numbers}

As we transition to the focus of consulting 'numbers' (argumentum ad numerum), there is notable discrepancy in this method between two lead figures on the issue, Alvin Goldman and David Coady.

Goldman refutes the strategy of 'going by the numbers' when assessing expert credibility. The approach relies heavily on the trustworthiness of crowd size as evidence to accredit an expert's position. Goldman criticizes 'going by the numbers' by offering examples that when applied, is questionable (such as in doctrinal communities and rumor mongering). Moreover, Goldman claims that more often than not, members in any given field tend to be influenced by similar biases which affects the novice's ability to know when expert opinion is distorted or validated by evidence. The fallacy of following the crowd is illustrated in these two examples because more people in agreement with one is not an opinion of independent thought. Goldman appeals to an axiom known as the non-independence principle that allows him to ground his opposition. The non-independence principle is described as two or more opinion holders sharing one source of information; this same source of information influences any one of their conclusions thereafter. As a result, the case for 'numbers' accrues no further grounds of validity when those who accept a proposition are impartial to an opinion already counted for. Intellectual autonomy is an important exercise for experts as it marks independent thought and different methods from which conclusions are reached. 
However, Coady offers a qualified defense for 'going by the numbers' by simply arguing the method should not be completely ruled out. When considering supplemental evidence in support of expert opinion, consulting 'numbers' can affect the non-expert's opinion in one of three ways: it can reduce, increase, or leave the initial opinion unaffected; the point Coady makes is that 'numbers' should be used cautiously. Coady also highlights the role of partnership in the enterprise of expertise, arguing that it is due to this interdependence of thought that scientific conclusions are reached. Expert consensus, Coady argues, is a product of teamwork due to the reliance on experts in areas outside of one's own. It is simply impossible for an individual to research all topics composited into a single research question. Coady offers a proposition that doesn't necessarily promote 'going by the numbers' in all cases, only that it shouldn't be ruled out.

In an attempt to mediate between both Goldman and Coady's dialogue on the 'numbers' approach, I would like to propose an auxiliary examination for when 'numbers' should specifically be consulted. I acknowledge good points made in each position which serves as motivation for me to bridge this gap between opinion. Goldman's non-independence principle, and Coady's claim that expertise is based on partnership, are both arguments I considered while examining the novice-expert problem. It was important for me to recognize that there is truth in both being hesitant to entirely trust crowd size for reasons such as non-independent thought and holding too many beliefs that are not appropriately defended. Hence, I propose only in instances where a position has an overwhelming (and undeniable) amount of 'numbers', should one consider 'going by the numbers'. An analogy I think proves my point can be seen in the degree of evidence required to find someone guilty of a crime. Much like in the court of law, there is a 
significant difference between being proven guilty by a 'preponderance of evidence' and 'beyond a reasonable doubt'; the difference lies in the 'numbers' (or percentage) whereupon guilt can be proven. Proof by a 'preponderance of evidence' is to prove guilt with greater than a $50 \%$ chance, whereas 'beyond a reasonable doubt' is proved with anywhere between $90-99 \%$ certainty. To expand on this analogy, the goal of finding someone guilty of a crime is substituted with the idea of which expert a novice is inclined to find more credible. I think this application can serve as a useful tool that can aid the novice in determining at which point the evidence presented undeniably justifies one position over another. All evidence considered, if a substantial amount of evidence directs the novice 'beyond a reasonable doubt', the novice can be assured that doubt is not as warranted had it instead been by a 'preponderance of evidence'. This is because the evidence required to substantiate 'beyond a reasonable doubt' is such that if a reasonable person were to consult said evidence, the only logical conclusion to form would be to find the person guilty/find an expert more credible. With that said, the legitimacy of numbers is rationalized within a legal context and adds to its use as an indicator for expertise.

Employing the proposition I offer above to the earlier example of climate change, I demonstrate its practical use in said discussion. As of current, the commonly (and popularly) cited numbers in support of and opposition of anthropogenic climate change is 97:3 (97\% being the percentage of those arguing it is largely human-induced)(The Rubin Report). Given that an overwhelming amount of climate scientists argue in favor of this position, all considered with sheer numbers, a novice is thus warranted in their inclination to be persuaded by such evidence. The numbers in this case are so convincing (with such a marginal number in opposition), it seems reasonable to derive a conclusion tending toward such evidence. There is a fundamental 
difference in using 'numbers' as an indicator of expertise and using 'numbers' as the sole rationale of one's conclusion.

\section{Conclusion}

In conclusion, my objective to mediate between the positions of Goldman and Coady provided above serve as an additional evaluation of the 'numbers' approach. My hope is that by clarifying the issue in terms of somewhat quantifiable measurements, the utility of 'going by the numbers' is rationalized. The ability for a novice to consult sheer crowd-size as an indication of expertise helps justify their credence of an expert. The accreditation is warranted on the fact that (as explained above) using 'numbers' along with other empirical evidence and literary techniques (i.e. argument form, diction, style of speech, fluency, etc.) endorses a justified position. By suggesting 'numbers' only be used in instances where there is significant disparity in views, the problem of 'going by the numbers' is curtailed and the possibility of misusing it is much reduced. The obligation of a scientific researcher is to accurately report their findings in an unbiased fashion, which is meant to prevent misrepresentation. Therefore, it is important that we guard ourselves from any possible manipulation or misinformation; to begin this process includes an assessment of Goldman's five sources expertise. The utility of this approach can be applied to other topics in the public arena such as: TSA policy, tax implementation, transportation projects, and healthcare for veterans and the disabled (to name a few) for future discussion. The relevance and applicability of this strategy can be favorable in developing opinion surrounding public policy in a time-sensitive manner that is both productive and efficient. 


\section{Works Cited}

I. Almassi, Ben. "Climate Change, Epistemic Trust, and Expert Trustworthiness (2012)."Academia.edu - Share Research. Academia.edu - Share Research, 2012. Web. 29 Nov. 2016.

II. Coady, David. What to Believe Now: Applying Epistemology to Contemporary Issues. Chichester, West Sussex: Wiley-Blackwell, 2012. Print.

III. Coady, David. "When Experts Disagree.” Episteme 3(1): 68-79.

IV. "FAQ 1.3 What Is the Greenhouse Effect?" IPCC Intergovernmental Panel On Climate Change. N.p., n.d. Web. 20 Mar. 2017.

V. Frierson, Dargan. "Fundamentals of Climate Change." (2013): n. pag. Google Slides. Web.

VI. GlennBeckBookList. Perf. Alex Epstein and Glenn Beck. The Moral Case for Fossil Fuels Alex Epstein Talks to Glenn Beck. Youtube, 16 May 2015. Web.

VII. Goldman, Alvin. 2001. “Experts: Which Ones Should You Trust?” Philosophy and Phenomenological Research 63(1): 85-111

VIII. Hardwig, John. 1985. "Epistemic Dependence.” Journal of Philosophy 82(7): 335-349

IX. Hardwig, John. 1991. "The Role of Trust in Knowledge.” Journal of Philosophy 88(12): 693-708 
X. Hardwig, John. 1994. "Toward an Ethics of Expertise.” In Professional Ethics and Social Responsibility, edited by Daniel Wueste. Lanham: Rowman \& Littlefield, 1994.

XI. The Rubin Report. Perf. Alex Epstein and Dave Rubin. Alex Epstein and Dave Rubin Discuss the Climate Change Debate (Full Interview). Youtube, 05 Aug. 2016. Web.

XII. Thomas, Matthew, and Luke Buckmaster. "Expertise and Public Policy: A Conceptual Guide." Parliament of Australia, 30 May 2014. Web. 29 Nov. 2016. 